\title{
Changing role of citizens in national environmental monitoring
}

\author{
Juhani Kettunen*, Jari Silander, Matti Lindholm, \\ Maiju Lehtiniemi, Outi Setälä and Seppo Kaitala
}

Finnish Environment Institute, Address: Mechelininkatu 34a, 00250 Helsinki, Finland

*juhani.kettunen@ymparisto.fi

\begin{abstract}
During the last few decades the role of citizens in environmental monitoring has changed remarkably in Finland. In this chapter, we briefly describe this change by using examples of both traditional and modern monitoring systems. According to our findings, there are at least four important drivers challenging traditional monitoring systems. First, the monitoring is undergoing a rapid process of globalisation and e.g. the systems that earlier focused on national problems are today controlled by European legislation or influenced by international problems, agreements and practices. Second, public obligations for monitoring have grown much more rapidly than economic resources and it requires the monitoring systems to have a new kind of ability to adapt to changes. Third, the migration of people from rural areas to towns has reduced the potential of a voluntary workforce. The forth driver is the aging of the volunteers. All drivers, without new monitoring strategies, challenge both the performance and geographical coverage of monitoring systems. We expect that a combination of new technologies, such as remote sensing, the Internet of Things and Big Data, can empower new groups of volunteers and increase the
\end{abstract}

\section{How to cite this book chapter:}

Kettunen, J, Silander, J, Lindholm, M, Lehtiniemi, M, Setälä, O and Kaitala, S. 2016.

Changing role of citizens in national environmental monitoring. In: Capineri, $\mathrm{C}$, Haklay, M, Huang, H, Antoniou, V, Kettunen, J, Ostermann, F and Purves, R. (eds.) European Handbook of Crowdsourced Geographic Information, Pp. 257-267.

London: Ubiquity Press. DOI: http://dx.doi.org/10.5334/bax.s. License: CC-BY 4.0. 
social impact and effectiveness of voluntary monitoring to fulfil our national and international obligations.

\section{Keywords}

Monitoring, Environmental, Drivers, Voluntary, Urbanisation, Globalisation

\section{Introduction}

Monitoring provides a sufficient level of information to support decisionmaking and comply with legal requirements. Volunteers are one of the greatest resources for enforcing environmental laws and regulations. Their role is everchanging as there are more obligations than ever before and fewer resources. There is a growing interest to motivate volunteers and increase the efficiency and social impact of monitoring.

The European Union has rapidly expanded and many new directives have come into force influencing environmental monitoring. The EU legislation has had an impact on the national legislation of all Member States and the daily lives of people living in the EU. Finland joined the EU in 1995, and today directives are influencing monitoring and their data dissemination practices. New monitoring projects, such as beach littering, have been established, and global obligations require the implementation of the INSPIRE Directive, which is based on the infrastructures for spatial information.

In the past ten years we have seen an immense increase in the number and volume of citizen science projects. The Internet, sensor technology and smart phones have made it easy to record observations with stamps on position and time, and the communication with data has become quick and easy. However, the participation of non-scientists in scientific research and data collection is not a new phenomenon. Well into the 19th century it was possible for non-professional scientists to contribute remarkably to scientific research (Haklay 2015). Significant scientific figures, such as Charles Darwin or Robert Boyle, may be considered, by today's standards, to have been non-professional scientists (Shapin 1994).

Urbanisation began relatively late in Finland and the process has been more rapid than in other European countries (Heikkilä 2003). The migration of people from rural areas to towns has reduced the potential of a voluntary workforce. Aging is another challenge, with the number of people over 60 being over four times higher than it was in 1900 (Official Statistics of Finland 2016). A whole new set of options have been used to solve challenges. The hydrological monitoring service is currently using new technologies and has increased marketing effort to recruit new observers. Modern monitoring projects, such as the algal watch, the Lake\&Seawiki and jellyfish, have utilised new mobile sensor technologies as well as social networking and processes to mitigate the impacts of drivers. Different monitoring projects seem to have different dominating drivers, as shown in the following table. 


\begin{tabular}{|l|c|c|c|c|}
\hline & Globalisation & $\begin{array}{c}\text { Grown } \\
\text { obligations }\end{array}$ & Urbanisation & Ageing \\
\hline Hydrology & 0 & 0 & - & - \\
\hline Birds & + & + & 0 & - \\
\hline Game animals & 0 & + & - & - \\
\hline Algal watch & + & + & 0 & 0 \\
\hline Lake\&Seawiki & + & + & 0 & 0 \\
\hline Jellyfish & 0 & 0 & 0 & 0 \\
\hline Beach litter & + & + & 0 & 0 \\
\hline
\end{tabular}

Table 1: Impacts of different drivers (+, 0, -; positive, neutral, negative) on selected monitoring projects in Finland.

\section{Selected monitoring projects}

\section{Hydrological monitoring - In service of infrastructure}

Local volunteers were actively recruited into hydrological monitoring already in the beginning of the 20th century when the predecessor of the national hydrological service in Finland was initiated. The observers received small premiums for their services, but their key motivation was their own interest in hydrological phenomena (Kuusisto 2008a). For more than a hundred years these amateur station agents completed important observations on hydrological parameters such as water level, frost, snow thickness, water equivalent and ice cover.

Observers have usually been engaged with monitoring activities for a long period of time, with some monitoring sites having been managed by the same family since the 1910s. In the beginning, the number of observed parameters was large. Between 1913 and 1931, the volunteers also collected samples on water quality. There were 200 stations for the analysis of transparency and light attenuation coefficients at seven different wave lengths (Kuusisto 2008b), and 100 locations in which samples for organic and inorganic suspended sediment, dissolved inorganic and organic matters, alkalinity and dissolved oxygen demand were collected. The intensive programme continued until 1932, when the Great Depression forced the closure of many monitoring programmes. However, the hydrological network started after the Second World War.

The national hydrological monitoring is an example of the volunteers being very efficiently organised. From the beginning the system has taken into account the role of volunteers as a part of the entire system. Today, a remarkable part of the hydrological monitoring is automated, but the network of over 300 observers covers the entire country and is closely developed to support real-time forecasting systems (Ymparisto 2015). Trained observers take care of the pre-designed 
network of monitoring sites. This makes the system reliable and cost-efficient even in remote areas. The system is facing a great challenge as many of the elderly volunteers have stepped down and more marketing efforts are needed in order to recruit new amateurs to replace them, especially in rural areas.

\section{Birds - Academic interest and hobby}

In Finland regular bird monitoring started in the early 20th century. Though the main motivation for this was academic, safeguarding some of the diminishing bird populations was another goal as well. Up to the 1970s, voluntary birdwatchers were mainly skilled amateur naturalists living in urban areas. A central organisation for regional societies was established in the middle of the 1970s and the Bird Atlas project started activating birdwatchers in rural areas (Santaoja 2013). The central organisation joined the global network of bird organisations, BirdLife International, in 1992. Since then the number of birdwatchers has increased remarkably and today involves about 12,000 birdwatchers (Birdlife 2015).

Until the 1970s, the partnership between the birdwatchers and the Museum (Natural History Museum of Finland) was very tight. Since then the Museum has concentrated on programmed, traditional bird monitoring and left the collection and filing of other voluntary observations to the NGOs (regional ornithological societies and BirdLife Finland. They have maintained and collected the data since then and share it in the BirdLife database, which is open to all registered users. Both programmed monitoring and other data are collected from birdwatchers.

The majority of the official bird monitoring is now coordinated by the Museum. It is based on the work of voluntary birdwatchers who have committed to a regular monitoring, following the given instructions on when, where and how to monitor certain bird species or an area. The monitoring data is used in the European Bird Census Council's (EBCC) various projects, e.g. in the assessment of Pan-European Common Bird Indices. The monitoring data and the random observations of birdwatchers are made available as part of the Global Biodiversity Information Facility (GBIF), which aims to make the world's scientific biodiversity data freely and universally available via the Internet for the benefit of science, society and a sustainable future.

The reasons for increasing birdwatching are manifold. Today the literature and other methods for the identification of species are very developed. Besides strengthening regional societies, BirdLife has been active in publishing and communications and it has introduced a large set of new activities, such as the Big Garden Birdwatch in January, which is aimed for all citizens, and a competition called the Battle of the Bird Towers in May, which is a competition mainly for birdwatchers. The share of women has grown, and birdwatching is nowadays also a hobby for families. The current number of bird observations 
collected by BirdLife and its member societies is annually over 1 million in Finland. Bird monitoring is a global programme that has also managed to attract many observers from rural areas.

\section{Game animals - Hobby and co-management}

Official monitoring of the population abundance of game has been carried out in cooperation between the Ministry of Agriculture and Forestry, the Finnish Game and Fisheries Research Institute and hunter organisations since the 1970s. The objective of the data collection is to produce a scientific foundation for sustainable hunting. Researchers plan the census and organise it together with hunter organisations, volunteer hunters do the actual fieldwork (Rktl 2015a) and the public research institute conducts the analyses and reports to the national and local administrations.

Different game species groups have their own monitoring programmes. Forest and mixed-forest agricultural game species are monitored through wildlife triangle schemes. More than 30 forest game species are monitored. The population and breeding success of waterfowl are monitored with pair counts in May and brood counts in July. Specific census methods have been developed for moose, large carnivores, seals, beavers and wild forest reindeer.

It is important to note that in Finland about 300,000 citizens pay the annual hunting management fee, and the number has doubled between 1960 and 2000 (Saarsalmi et al. 2014). In 1960 a majority of the hunters owned their hunting land, but today 60 per cent hunt on rented land of their hunting club or on government land. A large proportion of the landless hunters live in towns. According to the enquiry (Rktl 2015b) the total amount of active voluntary work by hunters in Finland in 2008 comprised 290 man-years. Hunters were on standby for a total of 1,800 man-years to assist in moose, white-tailed deer and large game animal emergencies, like traffic accidents.

An estimated total of 40,000 hunters participated in voluntary work in 2008. The value of the voluntary work without overheads was estimated at 7.1 million euros. The Game Management Associations estimated that some 20,000 people performed voluntary work in game monitoring. Voluntary work in nationwide game monitoring schemes was estimated to be 89 man-years, of which observation of large carnivores made up 40 man-years. Hunters covered around $900,000 \mathrm{~km}$ with their cars to carry out these nationwide game monitoring schemes. Even though there have been more obligations for volunteers in Finland, these challenges have been overcome via good cooperation.

\section{Algal Watch - Supporting other sources of information}

Algal watch was initiated in 1998 to better inform the public about blue-green algal blooms in the Northern Baltic Sea. In 2000, the first group of trained 
volunteers, sea scouts, started monitoring coastal and archipelago areas in Southern Finland (Rapala et al. 2012). The work supplemented the data collected by commercial ferries in the Alg@line network (Finmari 2015) established in 1995 (Rantajärvi et al. 2003). The aim of the network was partly educational, but it also set in a practice for citizen monitoring on blue-green algal blooms, bladder wrack and water transparency. Later on, the system was extended and since 2011 citizens have been able to report their observations on blue-green algal blooms, bladder wrack density and Secchi depth by using a mobile phone application called Algae watch (Mmea 2015).

The application includes instructions and stamping, i.e. registration of position and timing of the observation is done by the GPS of the phone. It is also possible to take a photograph and send it simultaneously with the observation. During the performed pilot trials, no service misuse was detected (Kotovirta et al. 2014).

Users of the application were motivated by sending them a notification of the algae situation and reminders to contribute to observations in the future too. From the user data it can be seen that citizen activity decreased towards the end of the summer, although blooms were still present. This is most likely due to the timing of summer holidays in Finland, which usually end by the beginning of August (Kotovirta et al. 2014).

\section{LakeఓSeawiki - modern tools and social networking}

Lake\&Seawiki (Jarviwiki 2015) is a wiki service about Finnish lakes and coastal sea areas. The concept was developed in the Finnish Environment Institute (SYKE) to promote people's engagement in the protection and monitoring of their nearby waters and to allow non-professionals to upload observations on water temperature, ice situation, algal blooms etc. The service has been running since 2011 and anyone can contribute. The users of the service can take part in discussions and maintain their own observation sites. Service is well marketed and currently the first that is managed by the communication department of SYKE.

The service is running on open source software and has low operation costs. The moderation and upgrades of software require one person-month a year. Furthermore, an office hour helpdesk is needed in June-August. In 2014, almost 280,000 users visited the service, with 200 contributing during summer months and 30 during winter months. They produce more than 9,000 observations annually. The number of visitors has increased annually by $25 \%$ (Kettunen et al. 2014).

Still, a large part of people contributing to the service are citizens who have earlier been recording their observations in their private notebooks. The service has given them a platform and acts as an archive and a visualizer for their observations. Some time series clearly show the impact of climate change on 
ice breakup. Measurements received from experienced amateur observers are generally of good quality and thus complement nicely the other parts of the monitoring system. The service started receiving observations from desktop computers. Today, the share of mobile phone and tablet users is growing and is expected to speed up the growth of the service.

\section{Jellyfish - Abundance unveiled for the 1st time}

In 2010 the Finnish Environment Institute started to collect jellyfish observations from the public to determine jellyfish distribution in Finnish waters and the factors affecting the bloom formation in late summer. The proposal for the monitoring came from the energy industry, which needed data on jellyfish abundances and predictions on conditions in which jellyfish form blooms, since these can affect power plants by possibly clogging the cooling water intake pipes.

Using only public observations, the monitoring of jellyfish distribution and abundance has now been ongoing for 5 years. Citizens have reported their observations via a web form, which is planned to be developed into a mobile application in the near future. In the form citizens are asked to estimate the jellyfish abundance on a two-level scale (few, clearly less than $<20$ individuals $\mathrm{m}^{-2}$ or a bloom, $>20$ individuals $\mathrm{m}^{-2}$ ), name the sea area where the observation was done, and if it was a coastal or an open sea observation. Wind and temperature estimates are also asked in the form.

This voluntary citizen science monitoring has revealed patterns in jellyfish abundance and distribution range in Finnish waters which would have otherwise been impossible to obtain. Further, the reported observations have also been used as a service when communicating with the power plants and other industry on the blooms close to their seawater intake areas. The challenge of this kind of monitoring is that it is highly dependent on the press releases informing citizens that observations are still (and continuously) needed. Without advertisements the number of observations is much smaller.

\section{Beach litter - Global outsourced monitoring}

Beach litter monitoring with the help of citizens started in Finland in 2012, when groups from Sweden, Finland, Estonia and Lithuania became partners in an EU-funded project. The aim was to implement the harmonised method for the first time around the Baltic Sea. The method used was based on a slightly modified UNEP protocol on beach litter survey (Cheshire, Adler \& Barbière 2009). The length of the beach had to be adjusted to central Baltic conditions, as well as the timing of surveys. The survey was implemented by the Finnish partner in the project: a local NGO (Keep the Archipelago Clean). 
For the survey to be successful, there has to be a dedicated group of people (at least two, but no more than 10) responsible for the survey during a certain time of the year on a certain beach. Each group has a contact person who collects the data and delivers it to the NGO in charge of the survey. In Finland the contact persons were people such as school teachers. Experience from the field has shown that the best commitment has come from schools, where the survey can be included as a part of environmental education.

The survey was a success in many ways, and the project was able to combine comparable data from macroscopic litter in different Baltic countries. The project received a lot of attention in national media, partly because Finland was categorised as the most littered country of the project. Some need of development/ improvement was also noted during the survey by the organiser. The type and location of the beach that will be surveyed has to be very carefully chosen. It is especially important when comparisons between countries are made. Each geographical area should have representative beaches from all beach categories: rural, urban or in between. It is especially important to identify what pressures are causing littering on the survey beach so that management is targeted correctly. Geographical expertise combined with local information of water currents, upwelling areas and other hydrographical aspects that may have an effect on the distribution of litter should also be included in the planning phase.

By using local citizens, the beach litter survey has proven to work so well that it is presently included in the Finnish monitoring plan for beach litter. The collaboration with the NGO is continuing, and new areas for monitoring are planned together with authorities.

\section{Lessons learned}

\section{Society under change}

There are some drivers in society that have had a strong influence on monitoring during the last few decades. One is urbanization, i.e. migration of people from rural areas to population centres. In Finland, this started as late as the 1960s, but the impact was stronger with the delay. Together with the rapid ageing of the Finnish population, it has gradually diminished the potential of getting new local volunteers for traditional hydrological and game animal monitoring. The lack of voluntary labour has worsened the situation with regards to tasks that require a constant standby or presence near the rural observation sites. Contrary to these continuous monitoring tasks, short-term monitoring efforts, such as wildlife triangle schemes, have revived again after years of downturn. This is explained by the intensive campaigns of hunter organisations. Short-term tasks are also better suited to the urban life-rhythm. The recent digitalisation of information systems has also made it possible to base the regulation of hunting on real-time data, which has encouraged voluntary 
monitoring work. Unlike the other traditional monitoring systems, birdwatching schemes seem to have benefitted from urbanisation. This has mainly followed from the unification and decentralisation of birdwatch organisations in the mid' 1970s (Santaoja 2013). The organisations have also been able to tackle the problem of ageing by developing new types of operational models based on ideas of competitions and other kinds of gamification, for example. Also, the educational and communicational material and tools supporting the birdwatch have greatly improved.

\section{Geographical scale and stage in policy formation have changed}

For the past 20 years, a strong driver changing both the ecological and environmental monitoring has been globalisation. It has changed the geographical scale of monitoring. After Finland joined the EU, the top-down regulations and the number of legal obligations have grown tremendously. Between 2000 and 2015 , the existing ecological and environmental monitoring was redesigned to be compatible with EU regulations, which has also somewhat changed the citizen science in Finland. After 2008, however, the national economy has weakened and the environmental administration has been forced to reduce costs and reconsider the entire monitoring system. In the latest strategy, the Ministry of Environment (2011) has indicated new guidelines for environmental monitoring in 2020. According to the guidelines, the imperatives are to reduce costs while improving timeliness and usability. The tools suggested by the strategy are automation and digitalisation, remote sensing, increased use of applications of citizen science and increased co-operation between the public, private and voluntary sectors.

\section{Operational models and the depth of engagement are different}

Before, the traditional monitoring systems were top-down oriented. The volunteers were given a task to collect observations, briefed on the phenomenon and given forms to fill. Today, the operational models are more diverse and the depth of the engagement of volunteers varies (Haklay 2015). We see it in the birdwatch and game monitoring. Competitions and campaigns have remarkably increased the participation. However, the activity of the hobbyists is not constant. For example, during 2006-2010 57 per cent of the 1.2 million bird observations were made by 100 so-called superobservers. The first years of Lake\&Seawiki have shown that people are most active in making observations and participating in wiki discussion while on vacation. In the beach litter watch we have seen that volunteers easily grow tired of observing if they do not have some additional motive.

All monitoring systems and the citizen science in them have their own life cycles. It seems probable that hydrological monitoring in its traditional form 
will be substituted by automation. However, it seems just as probable that Lake\&Seawiki has also brought new means for extending the geographical coverage of snow and ice observations. Earlier, we designed our monitoring on a national basis. Our new systems are more generic and can also be taken into use internationally.

\section{References}

Birdlife. fi. 2015. BirdLife Finland. Available from: http://www.birdlife.fi/english/index.shtml [4 August 2015].

Cheshire, A., Adler, E., \& Barbière, J. 2009. UNEP/IOC guidelines on survey and monitoring of marine litter, Nairobi: United Nations Environment Programme, Regional Seas Programme, University of Chicago Press, Chicago.

Finmari-infrastructure.fi. 2015. Alg@line - FINMARI. Available from: http:// www.finmari-infrastructure.fi/ferrybox [3 August 2015].

Haklay, M. 2015. Citizen Science and Policy: A European Perspective, 1st edn. Available from: http://www.wilsoncenter.org/sites/default/files/Citizen_ Science_Policy_European_Perspective_Haklay.pdf [4 August 2015].

Heikkila, E. 2003. Differential Urbanisation in Finland. Tijd Voor Econ \& Soc Geog Tijdschrift Voor Economische En Sociale Geografie, 94(1): 49-63 (Web).

Jarviwiki.fi, Lake \& Seawiki. Available from: http://www.jarviwiki.fi/wiki/ Main_page?setlang=en [5 August 2015].

Kettunen, J., Silander, J., \& Lindholm, M. 2014. Role of Citizens in the National Environmental Monitoring. In: Jørgensen, M., Brodersen, S., Dorland, J., \& Copenhagen (Eds.) 6th Living Knowledge Conference Copenhagen. Denmark, pp. 166-173.

Kotovirta, V., Toivanen, T., Järvinen, M., Lindholm, M., \& Kallio, K. 2014. Participatory surface algal bloom monitoring in Finland in 2011-2013. Environ Syst Res, 3(1): 24.

Kuusisto, E. 2008a. 'Observers' in The Water Cycle - Hydrological service in Finland 1908-2008. In: Kuusisto, E. (Ed.) 1st edn., Finnish Environment Institute, Karisto Oy, Hameenlinna, pp. 106-110.

Kuusisto, E. 2008b. 'Water quality monitoring 1911-1931' in The Water CycleHydrological service in Finland 1908-2008, Kuusisto, E. (Ed.) 1st edn., Finnish Environment Institute, Karisto Oy, Hämeenlinna, p. 40.

Luomus.fi. 2015. Bird monitoring | LUOMUS. Available from: http://www. luomus.fi/en/bird-monitoring [5 August 2015].

Ministry of the Environment. 2011. Monitoring Strategy of the State of the Environment 2020. Available from: https:/helda.helsinki.fi/handle/10138/ 41382? show [4 August 2015].

Mmea.fi. 2015. Environmental data - MMEA Testbed. Available from: http:// mmea.fi/cases/participatory-water-quality-measuring [3 August 2015]. 
Official Statistics of Finland (OSF). 2016. Population structure [e-publication]. ISSN=1797-5395. Helsinki: Statistics Finland [referred: 8.3.2016]. Access method: http://www.stat.fi/til/vaerak/index_en.html.

Rantajärvi, E., Ruokanen, L., Hällfors, S., Flinkman, J., Stipa, T., Suominen, T., Kaitala, S., \& Maunula, P. 2003. 'Alg@line in 2003: 10 years of innovative plankton monitoring and research and operational information service in the Baltic Sea' in Alg@line today, Rantajärvi, E. (Ed.) 1st edn., Meri no. 48, Finnish Institute of Marine Research, pp. 9-16.

Rapala, J., Kilponen, J., Järvinen, M., \& Lahti, K. 2012. Finland: Guidelines for Monitoring of Cyanobacteria and their Toxins. In: Current Approaches to Cyanotoxin Risk Assessment, Risk management and Regulations in Different Countries, Chorus, I. (Ed.), 1st edn., Federal Environment Agency (Umweltbundesamt), Germany, pp. 54-62.

Rktl.fi. 2015a. FGFRI - Monitoring game abundance. Available from: http:// www.rktl.fi/english/game/monitoring_populations/ [5 August 2015].

Rktl.fi 2015b. Hunters voluntary work. Available from: http://www.rktl.fi/en/ julkaisut/j/510.html [5 August 2015].

Saarsalmi, P., Koskela, T., Virtala, E., Murto, J., Pentala, O., Kauppinen, T., Karvonen, S., \& Kaikkonen, R. 2014. Terveyden ja hyvinvoinnin erot maalla ja kaupungissa vuonna 2013 - ATH-tutkimuksen tuloksia uuden kaupunkimaaseutu-luokituksen mukaan, 1st edn., THL. Available from: http://www. julkari.fi/handle/10024/125351 [4 August 2015].

Santaoja, M. 2013. For the love of Nature. Amateur Naturalists as Actors in Nature Conservation, Acta Universitatis Tamperensis 1853, Tampere.

Shapin, S. 1994. A social history of truth: civility and science in seventeenthcentury England, University of Chicago Press, Chicago.

Ymparisto.fi. 2015. Environment > Hydrological situation and forecasts. Available from: http://www.ymparisto.fi/en-US/Waters/Hydrological_situation_ and_forecasts [3 August 2015]. 